\title{
ANALISIS WACANA LINGKUNGAN DALAM DEBAT POLITIK KANDIDAT PILGUB KALIMANTAN TIMUR TAHUN 2018
}

\author{
Resya Famelasari \& Ibnu Asqori Pohan \\ resyafamela@ub.ac.id\&inbuasqoripohan@ub.ac.id \\ Program Studi Ilmu Politik, Fakultas Ilmu Sosial dan Ilmu Politik, Universitas \\ Brawijaya
}

\begin{abstract}
The Election of East Kalimantan Governor 2018 obtained a various assertion from society to resolve an environmental problem. Environmental Issue influenced the political debate in campaign period of four Candidate. This research emphasized on analyzing dominant environmental issue that is discoursed by tha election candidate and mapping the potential candidate whom most concern in environmental protection and improvement. The data of this study is news text on environmental discourse that has been screening and taken by electronic media divided into political debate I and II during 15 february until 15 May 2018. The Methodology of research used Critical Discourse Analysis Teun A Van Dijk: Sosio-Cognitif PerspectiveThe research finds that environmental discourse that emerged in the dominance by candidate no. 2 Syaharie Jaang-Awang F. Hidayat and Candidate no. 4 Rusmadi Wongso-Safaruddin. Candidate no. 2 discourses environmental program through altering function of mining holes become water resources and fishery sources, planting 200 thousand until 1 million trees in East Kalimantan, and revitalizing Mahakam Rivers and Lakes. Candidate no. 4 progam is mining permit re-arrangement, reclamation mining holes and Society Forest. The environmental policy discourse influenced by anthropocentrism perspective which is considered human interest rather than nature protection.
\end{abstract}

Keyword: Political Debate, East Kalimantan Governor Election, Critical Discourse Analysis, Environmental Issue

Abstrak

Pemilihan Gubernur Kalimantan Timur pada tahun 2018 ini mendapatkan berbagai tuntutan dari organisasi masyarakat utamanya pada penyelesaian persoalan lingkungan. Isu tersebut tentunya mempengaruhi perdebatan wacana dalam konteks kontestasi ide pada masa kampanye 4 kandidat terpilih. Media elektronik menjadi media utama sarana kampanye kandidat. Penelitian ini memfokuskan untuk menganalisis wacana lingkungan yang dominan muncul pada masing-masing kandidat dan memetakan kandidat yang paling memiliki concerndan program tentang perbaikan lingkungan. Data diperoleh dari penelusuran berita melalui media elektronik. Penelitian ini menggunakan metode studi Analisis Wacana Kritis Teun A van Dijk: Pendekatan sosio-kognitif terhadap berita kampanye kandidat melalui screening terhadap media elektronik selama 3 bulan masa kampanye. Pemberitaan dibagi kedalam dua periode yaitu berita debat 
141

Community: Volume 4, Nomor 2, Oktober 2018

ISSN: $2477-5746$

periode pertama dan kedua yang bermula pada tanggal 15 Februari hingga 15 Mei 2018. Hasil penelitian mendapati bahwa wacana pro-lingkungan yang muncul di dominasi oleh 2 kandidat yaitu Syaharie Jaang-Awang F. Hidayat dan Rusmadi WongsoSafaruddin unggul dalam dominasi konstruksi wacana lingkungan. Kandidat nomor urut 2 mewacanakan program pro-lingkungan melalui mengubah fungsi lubang eks-tambang pada sumber air dan perikanan, penanaman 200.000 hingga 1 juta pohon, revitalisasi sungai Mahakam dan danau, dan pengolahan SDA terbarukan. Pasangan kandidat Cagub no.4 menyatakan akan menata ulang izin pertambangan, reklamasi lubang ekstambang, dan perhutanan sosial. Dalam perspektif politik lingkungan maka isu dan wacana yang akan mempengaruhi public policy hanya dalam tahapan perspektif anthoposentrisme yang mendahulukan kepentingan manusia terlebih dahulu berbanding kepentingan perlindungan ala

Kata Kunci: Debat Politik, Pilgub Kaltim 2018, Analisis Wacana Kritis,Wacana Lingkungan

\section{Pendahuluan}

Analisis wacana kritis model Van Dijk digunakan untuk memahami kekuasaan, ideologi dan politik dibalik sebuah teks yang dikonstruk dan dibentuk oleh pembuat wacana. Beberapa penelitian menggunakan analisis model ini untuk mengamati dan menganalisis konteks sosial dibalik sebuah teks. Dalam penelitian Suciartini (2017) yang berjudul Analisis Wacana Kritis 'Semua Karena Ahok' Program Mata Najwa Metro TV bertujuan mendeskripsikan struktur makro, superstruktur, analisis semantik dari wacana yang berkaitan dengan kebijakan Ahok dan 1,5 kepemimpinan Ahok. Penelitian tersebut mayoritas mengamati struktur Bahasa tanpa menarik konteks sociokognitif dalam wacana yang muncul. Dalam Fitriyani (2011), jayanti (2014) keduanya meneliti komunikasi elit politik untuk memahami Bahasa politis yang digunakan elit dalam membangun pencitraan dalam menciptakan slogan politik dan mengukur konteks yang ingin dikontruksi dari sebuah slogan.

Dalam jurnal payuyasa (2017) juga menganalisa wacana di dalam program televisi matanajwa yang juga mendeskripsikan struktur Bahasa yang tercipta dalam program tersebut. Jurnal Bayu (2016) fokus pada isu reklamasi teluk benoa dalam website bali.tribunnews.com. Konteks sosio-kognitif muncul dalam penelitian tersebut untuk mengamati keterlibatan aspek ekonomi-politik dibalik wacana tersebut. Pemberitaan didapati bersifat subjektif dan tidak netral yang kemudian lebih mengutamakan atau berpihak kepada kepentingan ekonomi-politik investor dan pemerintahan.

Dalam penelitian ini akan menutupi kekurangan analisis wacana melalui pemilihan dan pengkhususan pada wacana lingkungan dalam debat politik pemilu dalam kampanye kandidat Gubernur yang bertujuan untuk memahami konteks pro-lingkungan 
yang ingin dikonstruk oleh calon elit politik tertentu dan menganalisis sosio-kognitif yang muncul dibalik teks yaitu lebih menekankan pada nilai yang dimiliki calon elit politik terhadap kelestarian dan perlindungan terhadap lingkungan. Apakah kandidat calon Gubernur Kalimantan Timur memiliki nilai transformasi dalam perlindungan terhadap lingkungan dalam menciptakan tata kalimat yang termasuk kedalam ecolinguistic. Objek studi yang diamati dalam penelitian ini adalah pemberitaan kampanye kandidat melalui media elektronik selama masa kampanye.

Pemilihan kepala daerah tahun 2018 diwarnai berbagai kritik dari pakar ligkungan karena pada tahun pilkada ini juga seiring dengan kadaluarsanya 906 Izin Usaha Pertambangan (IUP) di 17 provinsi penyelenggara pilkada dengan rentang masa berlakunya pada tahun 2017-2022. Momen Pemilu pada tahun 2018 ini tentunya diiringi dengan persoalan lingkungan yang sangat penting untuk diamati utamanya pada sektor pertambangan (Marlis:2018).

Data yang berasal dari Humas Forum Satu Bumi Mareta menjelaskan bahwa pada dasarnya luas geografis wilayah Kalimantan Timur yaitu 12.7 juta hektar, dalam angka tersebut 46\% wilayah atau setara dengan luasan 5.2 juta hektar telah diperuntukkan pertambangan, dan luas perkebunan seluas 3.37 juta hektar. Sedangkan peruntukan ruang hidup hanya tidak lebih dari 4.27 juta hektar yang menjadi wilayah pemukiman penduduk, dan fasilitas pasar, jalan, sekolah, rumah sakit, dll. Dengan tumpuan pendapatan daerah yang utamanya pada ekstraksi tambang dan perkebunan tentunya hal tersebut didukung oleh data pembagian wilayah geografis Kalimantan Timur.

Pemanfaatan ruang yang mayoritas digunakan untuk sektor pertambangan membawa pada dampak lingkungan yang dialami oleh provinsi Kalimantan Timur meliputi lahan terbuka bekas tambang telah memakan korban akibat tenggelam di lubang bekas tambang. Keseimbangan sistem ekologi juga terganggu mengakibatkan tanah longsor, ledakan tambang, keruntuhan tambang dan gempa. Kerusakan lingkungan dan lahan terjadi di Kalimantan Timur.Pada tahun 2016, terhitung 4000 lubang bekas tambang terbuka di daerah Kalimantan Timur yaitu sekitar 230 lubang berada di Kota Samarinda. Menurut Laporan Komnas HAM 25 nyawa anak tewas tenggelam di lubang bekas tambang tersebut. Data menurut Jaringan Advokasi Tambang (Jatam) Kalimantan Timur kedalaman lubang bekas tambang bervariasi dari $100 \mathrm{~m}$ dan 80 meter.

Permasalahan lingkungan dalam pemilihan pemimpin politik di Provinsi Kalimantan Timur menjadi permasalahan utama yang penting untuk diamati. Kerusakan lahan, Penyempitan Lahan akibat eksplorasi tambang, dan berbagai bencana yang muncul akibat kerusakan lahan tersebut juga mengalami kontestasi wacana dalam Pemilihan Gubernur Kalimantan Timur pada tahun 2018. Kandidat dalam Pemilihan Gubernur Kalimantan Timur Pada Tahun 2018 yaitu Nomer urut pertama; Pasangan Isran Noor- Hadi Mulyadi yang mendapat dukungan dari Partai Gerindra, PKS, dan 
PAN, kedua; Andi Sofyan Hardam-Nusyirwan yang didukung oleh Partai GolkarNasdem, ketiga; Rusmadi Wongso-Safaruddin yang didukung oleh PDIP dan Hanura,keempat, Syaharie Jaang-Awang F.Hidayat yang mendapatkan dukungan dari Partai Demokrat, PPP, dan PKB.

Penelitian ini akan fokus menganalisis kekuatan isu lingkungan yang diwacanakan oleh kandidat pasangan calon Gubernur Kaltim tahun 2018 dan bagaimana isu lingkungan menjadi agenda setiap pasangan calon dalam masa kampanye pilgub Kaltim. Metodologi yang digunakan dalam penelitian ini adalah melalui pemetaan terhadap pemberitaan melalui media elektronik. Pengamatan Media dilaksanakan melalui pemetaan isu lingkungan pada masing-masing calon melalui pemberitaan berbagai media elektronik dalam kurun waktu 3 bulan yang bermula pada tanggal 15 Februari hingga 15 Mei 2018 yang kemudian akan dianalisa kandidat paslon no urut berapa yang paling kuat mewacanakan perbaikan lingkungan di Kaltim dan bagaimana perbaikan lingkungan dapat terjadi melalui kerangka kebijakan yang diusung oleh masing-masing paslon.

Menurut Muhlhausler (dalam Yuniawan, 2017:291) menyebutkan bahwa terdapat 4 hal yang menghubungkan antara Bahasa dan lingkungan yaitu (1) Bahasa adalah bebas dan penuh arti. (2) Bahasa diciptakan oleh dunia; (3) dunia menciptakan Bahasa (dalam pandangan strukturalis dan post-strukturalis); (4) Bahasa merupakan interkoneksi dengan dunia (keduanya disusun dan menyusun tetapi juga bebas). Stibbe (2010:1) pada saat ini eco-lingustiac sangat dekat berhubungan dengan bagaimana Bahasa memainkan peran dalam membentuk, mempengaruhi, bahkan menghancurkan hubungan antara orang, kondisi lingkungan dan tempat tinggal.

Komunikasi Politik (Ramlan Surbakti,2010:152) ialah proses penyampaian informasi mengenai politik dari pemerintah kepada masyarakat dan juga sebaliknya dari masyarakat kepada pemerintah. Komunikasi politik juga meliputi proses dimana informasi politik yang relevan mengalam keberlanjutan untuk diteruskan dari satu bagian kepada bagian lainnya dalam sistem politik. Komunikasi Politik (Michael Rush dan Philip Althoff:2008:24) menentukan elemen dinamis dan menjadi bagian menentukan dari sosialisasi politik, partisipasi politik, dan pengrekrutan politik.

Mc Nair (dalam Yenrizal, 2017:2) menekankan komunikasi politik pada adanya intensi dan maksud yang kemudian Mc Nair menyimpulkan bahwa komunikasi politik terdiri dari: pertama; semua bentuk komunikasi yang dilakukan oleh politikus dan aktor politik lain untuk mencapai tujuan yang spesifik, kedua; komunikasi yang ditujukan kepada aktor politik kepada pemilih dan kolumnis, ketiga; komunikasi tentang para aktor politik dan sktifitas merega seperti yang dimuat berita, editorial dan berbagai bentuk media dan diskusi politik. Graber mendefinisikan komunikasi politik sevagai konstruksi pengiriman, penerimaan, dan proses pesan yang memiliki potensi langsung dan tidak langsung pada dampak politik. 
Kampanye politik menurut Rice dan Paisley (dalam Fatmawati, 2008:1 adalah bentuk komunikasi politik yang dilakukan seseorang atau sekelompok orang atau organisasi politik dalam waktu tertentu untuk memperoleh dukungan politik dari masyarakat. Pengertian Kampanye berdasarkan UU Nomor 1 Tahun 2015 tentang Pemilihan Umum Anggota dewan Perwakilan Rakyat, Dewan Perwakilan Daerah, dan Dewan Perwakilan Rakyat Daerah pada pasal 1 ayat 26 adalah kegiatan Peserta Pemilu untuk meyakinkan pada pemilih dengan menawarkan visi, misi, dan program Peserta Pemilu.

Untuk menganalisis konteks lingkungan dibalik sebuah Bahasa dalam kampanye kandidat Gubernur Kaltim 2018 digunakan Studi Wacana Kritis teun A.van Dijk: Pendekatan Sosio Kognitf. Studi wacana kritis merupakan suatu perspektif, suatu pengambilan posisi atau sikap dalam disiplin studi wacana yang melibatkan berbagai disiplin ilmu linguistik, psikologi, sejarah, sosial, dll. Asumsi dasar studi wacana kritis ialah bahwa Bahasa digunakan untuk beragam fungsi dan Bahasa mempunyai berbagai konsekuensi untuk memerintah, mempengaruhi, mendeskripsikan dan menggerakkan kelompok. Setiap penggunaan Bahasa mengandung konsekuensi-konsekuensi baik yang bisa diramalkan maupun yang tidak diharapkan. Bahasa digunakan untuk beragam fungsi dan mempunyai berbagai konsekuensi (Haryatmoko,2017:77).

Studi Wacana Kritis Van Dijk tidak hanya menyoroti ketidakberesan sosial namun juga menekankan juga studi tentang representasi mental dan proses-proses yang terjadi pada penggunaan Bahasa (cognition) ketika mereka memproduksi dan memahami wacana dan mengambil bagian dalam interaksi verba, juga sejauh mana mereka terlibat dalam interaksi pengetahuan, ideology, atau kepercayaan kelompok sosial tertentu. Pendekatan studi kognitif ini sekaligus memeriksa sejauh mana fenomena kognitif itu terkait dengan struktur wacana, interaksi verbal, peristiwa dan situasi komunikatif. Studi wacana kritis merupakan metodologi yang digunakan untuk menarik ideologi dan perspektif tata kelola lingkungan yang diwacanakan oleh pasangan kandidat untuk menyuarakan isu lingkungan (Haryatmoko,2017:80).

Proses komunikasi politik dalam kampanye keempat pasangan calon Gubernur Kalimantan Timur diamati melalui pemberitaan media elektronik yang memuat tentang informasi visi dan misi setiap paslon, mengamati hasil debat paslon yang diberitakan oleh media, dan berbagai informasi tentang opini paslon dalam menyikapi berbagai persoalan lainnya dalam konteks menaikkan isu atau wacana tertentu yang akan menjadi concern dalam pemerintahan.

\section{Metodologi}

Metodologi yang digunakan dalam penelitian ini bersifat deskriptif kualitatif. Dalam perolehan data primer, peneliti menggunakan intelligence media yang mampu secara otomatis memetakan struktur wacana lingkungan yang tercipta dan dikomunikasikan oleh pasangan calon Gubernur Kaltim. Proses pencarian data 
penelitian dilakukan dengan menggunakan software intelligence media yang bertujuan untuk mengumpulkan pemberitaan media yang sifatnya online yang membahaskan atau berkaitan dengan penggunaan isu lingkungan. Untuk memilih dan melakukan pemilahan terhadap pemberitaan kampanye para kandidat, pertama; membatasi time framing pada software pencarian berita bermula pada tanggal 15 Februari 2018 hingga 15 mei 2018, kedua; untuk menscreening berita, maka media tersebut dapat melakukan screening melalui penggunaan keywords. tahapan selanjutnya yaitu menganalisis trend wacana utama yang muncul dan mendeskripsikan argumentasi masing-masing paslon terkait wacana tersebut. Analisis wacana lingkungan dalam konteks Pilgub Kaltim 2018.

\section{Pembahasan dan Hasil}

Kandidat nomor urut pertama adalah Andi Sofyan Hasdan dan Rizal Effndi yang mendapatkan dukungan dari Partai Golkar dan Nasdem. Andi Sofyan Hasdam merupakan cagub Kaltim yang merupakan dokter spesialis saraf dan Rizal Effendi menggantikan Nusyirwan yang merupakan walikota Balikpapan ke-10. Kandidat nomor urut 2 yaitu Syahrie Jaang- Awang Ferdian Hidayat yang didukung oleh partai democrat, PKB, dan PPP. Syahrie Jaang merupakan walikota Samarinda untuk masa jabatan 2010-2015 dan Awang Ferdian Hidayat merupakan anggota DPR RI periode 2014-2019.

Kandidat nomor urut 3 yaitu Isran noor-Hadi Mulyadi yang didukung oleh Gerindra-PKS-PAN, Isran Noor merupakan Bupati Kutai Timur pada 2009 hingga 2015. Sedangkan pasangan Isran Noor yaitu Hadi Mulyadi merupakan anggota DPR-RI periode 2014-2019 dari Partai PKS. Hadi Mulyadi harus meninggalkan Jabatan Wakil Ketua Komisi DPR RI hingga maju menjadi wakil gubernur dalam Pilgub Kaltim 2018. Pasangan no.4 adalah Rusmadi Wongso dan Safaruddin yang didukung oleh PDIP dan Hanura. Rusmadi datang dari kalangan birokrat di kaltim yang menjabat Sekda Kaltim sejak 10 februari 2016 dan sebelumnya adalah kepala Bappeda Kaltim. Elit politik beretnis Jawa ini mengumumkan maju pada pilgub altim tahun 2018 berduet dengan Kapolda Kalimantan Timur, Irjen Pol. Safaruddin.

Dapat disimpulkan bahwa kandidat calon gubernur kaltim mayoritas adalah datang dari kalangan birokrat yang telah menduduki jabatan dalam kekuasaan politik. Bagaimana pola wacana yang berkembang terkait dengan isu penyelamatan lingkungan akan dibahaskan melalui isu lingkungan utama yang muncul dalam debat kampanye kandidat yaitu:

\section{Dalam debat perdana cagub Kaltim 2018 pada tanggal 25 April 2018}

Teks berita yang terpilih dalam penelitian ini terlebih dahulu mengalami proses screening dan penyaringan terhadap teks berita online yang menyentuh langsung pada isu upaya penanggulangan dampak lingkungan. Teks Berita 1. Minim Ketegangan, Seluruh Paslon Bidik Hilirisasi. Pada tanggal 26 April 2018 diterbitkan secara online 
melalui lamanhttp://kaltim.prokal.co/read/news/329419-minim-ketegangan-seluruhpaslon-bidik-hilirisasi.html

Pasangan nomor urut 1, Andi Sofyan Hasdam-Rizal Effendi menyampaikan tiga program unggulan. Yakni, subsidi jaminan kesehatan untuk warga demi pemerataan pelayanan kesehatan. Di sektor pendidikan, mereka menyoroti belum terbentuknya perwakilan Dinas Pendidikan provinsi di setiap kabupaten/kota untuk menangani pendidikan tingkat SMA sederajat.

"Selain itu, honor guru honorer yang selama ini hanya Rp 1,3 juta, akan kami naikkan menjadi Rp 2,5 juta," kata Sofyan. Rizal menimpali, program ketiga ada stimulan senilai Rp 900 juta sampai Rp 1 miliar untuk setiap desa. Yang tujuannya untuk merangsang perekonomian, khususnya bidang pertanian dan perkebunan.

Pasangan Nomor 1 pada umumnya memfokuskan pada program jaminan kesehatan,

pendidikan, dan program pemberian dana desa

"Isu yang berkembang di Kaltim saat ini adalah menurunnya pendapatan dengan menurunnya APBD kita. Maka dari itu langkah yang akan kami lakukan adalah transformasi ekonomi," kata Jaang. Dia menyebutkan daratan dan lautan Kaltim begitu luas. Sehingga potensi pertanian, perkebunan, peternakan, dan perikanan memberikan janji peningkatan terhadap konstruksi keuangan pada masa mendatang.

Selanjutnya, memberikan anggaran $\mathrm{Rp} 1$ triliun untuk percepatan dan pemerataan pembangunan di tingkat desa, kampung, dan kelurahan. Serta memberikan beasiswa terhadap total 10 ribu pelajar di Kaltim. Ferdian Menambahkan, salah satu program lainnya adalah program padat karya. Yakni, memberdayakan masyarakat, sehingga dapat menurunkan angka kemiskinan.

Pasangan No2. Juga tidak banyak perbedaan yait peningkatan potensi perkebunan, peternakan dan perikanan, pemberian dana desa, dan peningkatan lapangan kerja. Pasangan No.3 pembangunan ekonomi desa dan pendidikan dengan pemberian beasiswa

"Visi-misi kami akan menuju Kaltim yang berdaulat. Dengan begitu, program kami adalah program yang berani untuk Kaltim yang berdaulat," kata Hadi Mulyadi. Dia menambahkan, jika terpilih, pasangan ini akan melakukan terobosan yang selama ini belum terlaksana dengan baik. Salah satunya memberikan 65 ribu beasiswa secara terukur dan terencana. Bukan hanya asal memberi, tapi juga ada ikatan dinas bagi penerimanya. 
"Kami juga tak akan membangun proyek-proyek mercusuar. Kami akan lebih fokus pada perkembangan perekonomian di desa. Kami akan bangun jalan-jalan produksi yang akan memberikan dampak langsung terhadap masyarakat luas," ujarnya, menutup kesempatan bicara.

Pasangan nomor 4, Rusmadi-Safaruddin, juga punya empat kiblat untuk membangun Kaltim melalui pembangunan infrastruktur daerah dan pengawasan anggaran.

"Kami akan mendorong kemajuan pembangunan daerah. Kami akan bangun kemandirian perekonomian di desa melalui bantuan Rp 5-10 miliar per desa," kata Rusmadi. Dia juga akan fokus pada kelengkapan infrastruktur di daerah, seperti penyediaan jalan, listrik, dan air. Penanganan banjir di Samarinda dan Balikpapan juga menjadi fokus kerjanya jika terpilih kelak.

Safaruddin melanjutkan membacakan program kerja mereka. Salah satu yang menjadi fokusnya adalah menjadikan Kaltim aman. Salah satu yang dia tegaskan adalah mengawal agar tak ada lagi penyimpangan-penyimpangan. "Itu tugas saya agar anggaran benar-benar sampai ke masyarakat," terangnya.

Melalui analisa teks perdebatan pertama tidak satupun program utama setiap pasangan menyentuh wacana lingkungan padahal isu ini kritis harus diselesaikan kandidat karena kerusakan alam Kalimantan Timur yang terjadi akibat pertambangan. Dalam sesi pertanyaan terungkap beberapa komitmen perbaikan lingkungan hanya dari beberapa kandidat yaitu;

1. Kandidat nomor urut 4 yaitu Rusmadi berkomitmen untuk menata ulang izin pertambangan

'Dia melanjutkan, ada 807 IUP yang tidak clear and clean (CnC). Kemudian, akhir masa dia menjabat, masih ada 407 IUP belum CnC. "Ini sesuatu yang luar biasa. Ke depan, SDA harus dimanfaatkan secara bijak. Memperhatikan lingkungan karena pemanfaatan SDA harus memberikan kesejahteraan dan tidak merusak lingkungan," ujarnya.

2. Revitalisasi sungai Mahakam dan danau, komitmen dari pasangan nomer urut 2

"Jaang optimistis mampu memberikan solusi jika terpilih jadi gubernur. "Saya maju karena saya ingin selesaikan masalah banjir. Bukan hanya di Samarinda, tapi juga di daerah lain," ujarnya.

Menurutnya, persoalan banjir di Samarinda tak bisa diselesaikan Pemkot Samarinda saja. Sebab, berkaitan dengan kabupaten/kota lain. Tanggung jawab gubernur adalah mengurusi DAS Mahakam. Harus ada pengerukan dari Kukar, Samarinda, sampai Balikpapan. Selain itu, fungsi danau dan bendali harus dimaksimalkan. Dia banyak mendapati danau di Kubar yang ditumbuhi tanaman jagung." 


\section{Dalam debat kedua pada tanggal 9 Mei 2018}

Melalui teks berita 2. Pada tanggal 9 Mei 2018 berjudul Debat Pilkada Kaltim, Ketua KPUD: Ini jadi Pencerahan bagi pemilih, diambil pada lamanhttps:/www.inews.id/daerah/kaltim/117409/debat-pilkada-kaltim-ketua-kpud-inijadi-pencerahan-bagi-pemilih

pasangan nomor urut 1, Andi Sofyan Hasdam-Nusyirwan, menilai kondisi Kaltim masih memprihatinkan. Mengutip dari data statistik, pada 2017, angka kemiskinan masih mencapai 6,08 persen. Meskipun angka kemiskinan sudah menurun 2,3 persen dibandingkan 2016, namun kenyataan di lapangan berbeda.

Paslon nomor urut 2, Syaharie Jaang-Awang Ferdi siap mewujudkan Kaltim yang berdaya saing, mandiri, maju dan sejahtera, serta berkelanjutan dengan berbasis sumber daya alam terbarukan. Paslon ini juga akan mengalokasikan Rp1 triliun per tahun untuk infrastruktur dasar, beasiswa pada pelajar, membangun ekonomi pedesaan dan menanggulangi kemiskinan.

Paslon nomor urut 3, Israan Noor-Hadi Mulyadi memaparkan, visi mereka untuk membangun Kaltim berdaulat. Program-program yang disiapkan di antaranya membangun $500 \mathrm{~km}$ jalan produksi yang belum mendapat perhatian pusat dan daerah, 500.000 lapangan kerja, Rp500 miliar modal usaha, 6.500 beasiswa dengan ikatan dinas, khususnya tenaga kesehatan dan pendidikan, dan membangun 25.000 rumah untuk masyarakat prasejahtera dan nelayan. Program-program ini dinilai bisa mengentaskan kemiskinan.

Selanjutnya pasangan nomor urut 4, Rusmadi-Safaruddin mengatakan, mereka akan meningkatkan kesejahteraan masyarakat dan menekan angka pengangguran. Pasangan ini telah merancang sejumlah program menyangkut ekonomi rakyat, membangun 50.000 hektare perkebunan rakyat, kampung produksi, pembangunan kawasan industri, mendorong investor berinvestasi, bantuan permodalan untuk UMKM dengan suku bunga rendah tanpa agunan, dan juga jaminan hidup layak bagi masyarakat miskin dan penyandang disabilitas.

Analisis teks pada berita yang memuat program-program keempat pasangan calon masih tidak memuat Bahasa yang pro-lingkungan hanya beberapa istilah tentang berkelanjutan dan sumber daya alam terbarukan.

Teks Berita ke-3 pada 13 Mei 2018, Debat Kandidat Pilgub Kaltim, Rusmadi vs Isran Soal Lingkungan http://detakkaltim.com/index.php/2018/05/13/debat-kandidat-pilgubkaltim-rusmadi-vs-isran-soal-lingkungan/

Rusmadi dalam kesempatan silaturrahmi ke masyarakat juga terus menjelaskan visi misi tentang lingkungan. Salah satunya, dengan menargetkan memberikan lahan perhutanan sosial 600 ribu hektar. 
Perhutanan sosial ini sudah berhasil dijalankan Rusmadi saat menjabat Kepala Bappeda Kaltim dan Sekda. Dimana pada tahun lalu, ia telah menyerahkan sertifikat lahan perhutanan sosial di Berau.

"Ada 4 kampung saya serahkan SK (Surat Keputusan) Hutan Desa atau Hak Pengelolaan Hutan Desa (HPHD) di Berau pada tahun lalu," ujar Rusmadi ketika menghadiri perayaan adat Lomplai di Desa Nehas Liah Bing, Kecamatan Kongbeng, Kabupaten Kutai Timur beberapa waktu lalu..

Rusmadi juga mendapat kepercayaan warga Balikpapan untuk mengatasi banjir di kota tersebut. Ia mampu menjawab masalah banjir di daerah itu yang disebabkan masifnya pembukaan lahan perumahan, akibat izin dari pemerintah daerah tersebut. Rusmadi kepada setiap masyarakat di Kaltim agar berjuang bersama membangun Desa dan Kota. Karena, tanggung jawab pembangunan tak hanya seorang Gubernur. Tapi juga tanggung jawab Bupati dan Wali Kota serta masyarakat.

Isu lingkungan menjadi bagian penting visi dan misi Rusmadi-Safaruddin. Bahkan sudah disebut-sebut di Kaltim Bermartabat, yakni berdayasaing, mandiri, aman, sejahtera dan berkelanjutan. Kata berkelanjutan itu menekankan bagaimana sisi pandang Rusmadi-Safaruddin, bahwa yang kelak mereka lakukan dalam pembangunan, selalu dipikirkan untuk menunjang berkelanjutan.

Teks Berita ke-4 pada tanggal 14 mei 2018 , Rusmadi tolak 'rayuan' pengusaha melalui artikel media http:/gerbangkaltim.com/

"Potensi karst Sangkulirang Mangkalihat ini sangat besar yang memiliki agroekosistemnya 1,68 juta itu hanya miliki bentang utama 307,8 ribu hektar. Tetapi pengalaman kita berisiko lingkungan tentu kita perlu kehati-hatian, dari aspek lingkungan," kata Rusmadi

Ketegasan Rusmadi yang ingin reklamasi berbeda dengan Jaang yang masih mau mempertimbangkan permintaan pihak lain untuk menjadikan lubang tambang sebagai sumberair bersih dan lahan perikanan di kota Samarinda.

Teks Berita ke-5, Janji Syaharie Jaang-Awang Ferdian Tangani Kerusakan Lingkungan di Kaltim pada tanggal 9 Mei 2018 https://daerah.sindonews.com/

"Salah satu program yang akan dilakukan adalah dengan penanaman sekitar 200 ribu pohon di seluruh Kalimantan Timur," kata Awang Ferdian Hidayat

Menurut Awang Ferdian, pihaknya akan menanam pohon aren untuk mewujudkan program 1 juta pohon yang akan dicanangkan. "Karena untuk pohon aren tidak sulit penanganannya," ungkap Awang

Pada debat periode kedua ini mulai memunculkan berbagai wacana yang menyentuh persoalan lingkungan di Kalimantan Timur yaitu melalui pengelolaan teks berita kedua dan keempat memunculkan pembahasan tentang; 
Community: Volume 4, Nomor 2, Oktober 2018

ISSN: $2477-5746$

1. Perhutanan Sosial seluas 600 ribu hektar yang diusung oleh kandidat nomer 4

2. Reklamasi lubang bekas tambang yang diusung oleh kandidat nomer 4

3. Penggunaan lubang bekas tambang menjadi sumber air bersih dan lahan perikananyang diusung oleh kandidat nomer 2

4. Program penanaman 200 ribu pohon hingga 1 juta pohon di seluruh Kalimantan

Timur oleh kandidat no.2

Komunikasi politik dapat berbentuk komunikasi yang dilakukan oleh politikus dan aktor politik lain untuk mencapai tujuan yang spesifik dan komunikasi yang ditujukan kepada aktor politik kepada pemilih dan kolumnis, dan jugakomunikasi tentang para aktor politik dan aktifitas mereka seperti yang dimuat berita, editorial dan berbagai bentuk media dan diskusi politik. Dalam komunikasi politik kandidat yang dilaksanakan dalam periode kampanye pemilihan Gubernur Kalimantan Timur tahun 2018 dapat diperoleh bahwa isu lingkungan juga menjadi salah satu perdebatan yang minim untuk dibicarakan diantara kandidat paslon. Transformasi nilai yang prolingkungan tidak terlalu tampak dalam perdebatan wacana.

Table 1. Wacana Lingkungan dalam Kampanye Pilgub Kaltim 2018

\begin{tabular}{|c|c|c|c|c|}
\hline $\begin{array}{l}\text { Isu/Wacana } \\
\text { Lingkungan } \\
\text { Utama }\end{array}$ & $\begin{array}{l}\text { Paslon No.1 } \\
\text { Andi Sofyan } \\
\text { Hasdam- } \\
\text { Nusyirwan }\end{array}$ & $\begin{array}{l}\text { Paslon No.2 } \\
\text { Syaharie Jaang- } \\
\text { Awang } \\
\text { F.Hidayat }\end{array}$ & $\begin{array}{l}\text { Paslon No.3 } \\
\text { Isran Noor- } \\
\text { Hadi Mulyadi }\end{array}$ & $\begin{array}{l}\text { Paslon No.4 } \\
\text { Rusmadi } \\
\text { Wongso- } \\
\text { Safaruddin }\end{array}$ \\
\hline $\begin{array}{l}\text { Crude Palm } \\
\text { Oil }\end{array}$ & $\begin{array}{l}\text { 'Hilirisasi } \\
\text { CPO' }\end{array}$ & $\begin{array}{l}\text { 'Industri hilir } \\
\text { berwawasan } \\
\text { ingkungan' }\end{array}$ & Hilirisasi sawit & $\begin{array}{l}\text { 'Hilirisasi } \\
\text { Industri Sawit' }\end{array}$ \\
\hline $\begin{array}{l}\text { Lubang Eks- } \\
\text { Tambang }\end{array}$ & & $\begin{array}{l}\text { 'lubang tambang } \\
\text { sebagai sumber } \\
\text { air bersih dan } \\
\text { perikanan' }\end{array}$ & & $\begin{array}{l}\text { 'reklamasi } \\
\text { lubang tambang' }\end{array}$ \\
\hline Pertambangan & & $\begin{array}{l}\text { 'berkelanjutan } \\
\text { berbasis SDA } \\
\text { terbarukan' }\end{array}$ & & $\begin{array}{l}\text { 'penataan } \\
\text { perizinan } \\
\text { tambang' }\end{array}$ \\
\hline $\begin{array}{l}\text { Jalan dan } \\
\text { banjir }\end{array}$ & & $\begin{array}{l}\text { 'Pengerukan } \\
\text { pemeliharaan } \\
\text { sungai } \\
\text { mahakam' } \\
\text { 'Program } \\
\text { penanaman } \\
\text { 200.000- } \\
\text { ljutapohon' }\end{array}$ & & $\begin{array}{l}\text { 'Mengerahkan } \\
\text { pembiayan } \\
\text { bersumber dari } \\
\text { APBD' } \\
\text { 'Pembiayaan } \\
\text { dari CSR } \\
\text { Perusahaan di } \\
\text { Kaltim' }\end{array}$ \\
\hline Kehutanan & & & & $\begin{array}{l}\text { Hutan Sosial } \\
600.000 \text { ha }\end{array}$ \\
\hline
\end{tabular}


Sumber: diolah oleh penulis (2018)

Dalam membahaskan isu utama yang berkaitan dengan industri kelapa sawit, hampir semua kandidat menyatakan akan mewujudkan hilarisasi industri kelapa sawit, dan pasangan calon no.4 menyatakan 'replanting sawit' dan 'perluasan 50 ha sawit'. Hilirisasi industri kelapa sawit disepakati oleh semua kandidat. Dalam konteks Kalimantan timur memang industri ini dapat menjadi peralihan dalam menggantikan eksplorasi tambang. Hilirisasi sawit berarti pemerintah ingin meningkatkan kapasitas industry untuk mengolah CPO menjdi produk bernilai tambah yang dapat menjadi produk ekspor dan barang substitusi impor.

Perdebatan tentang wacana lingkungan banyak diutarakan oleh pasangan calon dengan no.urut 2 dan 4 yaitu Syaharie Jaang-Awang F. Hidayat dan Rusmadi WongsoSafaruddin yang memiliki kekuatan dalam wacana lingkungan. Persoalan bekas tambang menjadi isu penting mengingat bekas tambang telah mengakibatkan 22 korban meninggal. Dalam konteks perdebatan politik terkait dengan isu/wacana persoalan lubang bekas galian tambang, hanya paslon no.2 dan paslon no.4 yang memiliki pandangan tentang penanganan bekas tambang. Pendekatan mereka juga berbeda dalam mengatasi persoalan lubang tambang tersebut pada paslon Syaharie Jaang-Awang F.Hidayat lebih menekankan pengalihan fungsi lubang tambang untuk perkebunan dan perikanan. Sedangkan paslon no.4 yaitu Rusmadi Wongso-Safaruddin mengusung penyelesaian melalui reklamasi tambang seperti tuntutan dari beberapa LSM lingkungan. Beberapa LSM pada dasarnya melakukan penuntutan untuk diadakannya reklamasi terhadap lahan bekas tambang.

Isu pertambangan merupakan persoalan yang krusial dan menjadi pengamatan karena persoalan terbatasnya lahan eksplorasi maka Kaltim dituntut untuk meninggalkan eksplorasi dan beralih pada sektor perekonomian lainnya. Argumen dalam kampanye mengungkapkan bahwa terkait isu pertambangan, pasangan calon no. 4 menyatakan akan menata ulang izin pertambangan. Dalam menyikapi persolan jalan yang rusak dan bencana banjir paslon no.urut 2 yang terungkap berargumen mengenai hal itu dengan mengatasi persoalan melalui penanaman 200.000-1 juta pohon dan upaya revitalisasi sungai Mahakam. Sedangkan Rusmadi Wongso menekankan penanganan banjir dilakukan melalui mengerahkan pembiayan bersumber dari APBD dan pembiayaan dari CSR Perusahaan di Kaltim.

Isu lingkungan dalam perdebatan politik esensinya hanya membicarakan isu lingkungan sebagai program jangka pendek bukan pada program perbaikan lingkungan yang berdampak luas secara jangka panjang. Isu ini juga kurang memberikan popularitas yang cukup untuk memobilisasi suara kandidat. Padahal dalam konteks Kalimantan Timur, diharapkan mampu memberikan dampak yang berarti bagi perbaikan lingkungan untuk mengatasi kerusakan dan degradasi alam yang secara masif terjadi disana. Isu lingkungan hanya menawarkan solusi di permukaan yang siapapun 
kandidat yang memenangkan Pemilu tidak begitu berdampak pada perbaikan alam. Artikel ini mengingatkan esensi perdebatan pemilu juga harus mempertajam perdebatan dalam penyelamatan lingkungan khususnya untuk daerah yang terdampak degradasi alam secara besar-besaran. Dalam perspektif politik lingkungan maka isu dan wacana yang akan mempengaruhi public policy hanya dalam tahapan perspektif anthoposentrisme yang mendahulukan kepentingan manusia terlebih dahulu berbanding kepentingan perlindungan alam.

\section{KESIMPULAN}

Berbagai persoalan lingkungan di Kaltim memerlukan perhatian serius dari Calon Gubernur Terpilih Pada Tahun 2018. Kaltim harus menghadapi kerusakan lingkungan akibat lubang bekas tambang, laju deforestasi yang cepat, dan permasalahan bencana alam akibat kerusakan lingkungan. Lubang bekas tambang juga telah menewaskan banyak korban. Permasalahan tersebut telah mendapatkan tanggapan dari masing-masing kandidat yang berkontestasi dalam Pilgub Kaltim 2018. Melalui Analisis Wacana Kritis Teun A van Dijk: Pendekatan sosio-kognitif terlihat bahwa dalam suatu Bahasa memuat konteks sosio-kognitif yang mampu mempengaruhi dan mengkonstruksi kondisi alam atau lingkungan. Wacana lingkungan yang muncul di dominasi oleh persoalan hilirisasi industri kelapa sawit yang diusung oleh semua kandidat hampir semua kandidat menyatakan akan mewujudkan hilarisasi industri kelapa sawit untuk meningkatkan kedaulatan pemerintah dalam sektor sawit. Kandidat nomor urut 2 mewacanakan program pro-lingkungan melalui mengubah fungsi lubang eks-tambang pada sumber air dan perikanan, penanaman 200.000 hingga 1 juta pohon, revitalisasi sungai Mahakam dan danau, dan pengolahan SDA terbarukan. Pasangan kandidat Cagub no.4 menyatakan akan menata ulang izin pertambangan, reklamasi lubang eks-tambang, perhutanan sosial. Melalui analisis berita kampanye kandidat yang bermula pada tanggal 15 Februari hingga 15 Mei 2018 dapat disimpulkan bahwa Pasangan Calon No. Urut 2 dan 4 yaitu Syaharie Jaang-Awang F.Hidayat dan Rusmadi Wongso-Safaruddin unggul dalam dominasi konstruksi wacana lingkungan. Bahasa merupakan interkoneksi dengan dunia (keduanya disusun dan menyusun tetapi juga bebas) dalam hal ini Bahasa juga berarti menyusun realitas politik Kalimantan Timur Kedepannya.Meskipun dampak nyata tentunya belum dapat terukur. Komunikasi Politik tentunya perlu dibangun dengan hati-hati dalam konteks pemilu dalam bentuk visi, misi, dan program karena hal tersebut dapat berdampak pada fokus kebijakan dan agenda setting yang akan dirancang oleh Gubernur terpilih. Krisis lingkungan dan alam di Kalimantan Timur seharusnya menjadi landasan untuk meningkatkan efektivitas dan penciptaan inovasi pelayanan publik untuk mensejahterakan masyarakat dan menjaga alam sekitar. Penelitian ini mengharapkan menjadi acuan pemilih di Kalimantan Timur 
sebagai rekomendasi dan rujukan memilih seorang Calon Gubernur yang peduli dan pro-terhadap perlindungan lingkungan

\section{DAFTAR PUSTAKA}

Bayu, I Gusti Ngurah Agung,.et al. 2016. Analisis Wacana Kritis Tentang Isu Reklamasi Teluk Benoa Dalam Website Bali.Tribunnews.Com. e-proceeding management: Vol.3, No.3

Dr. Haryatmoko. 2016. Critical Discourse Analysis: Landasan Teori, Metodologi, dan Penerapan. Jakarta: PT. RajaGrafindo Persada

Fatmawati. Strategi Komunikasi Pada Kampanye Politik (Studi Fenomenologi Pengalaman Strategi Komunikasi Karsa dan Tim Sukses Pada Kampanye Politik dalam Memenangkan Pilkada Jawa Timur. Bunga Rampai Komunikasi Indonesia

Fitriyani, Amalia. 2011. Analisis Wacana Kritis Pencitraan Susilo Bambang Yudhoyono Sebagai Politikus Dalam Buku Pak Beye dan Politiknya. Terbitan PT.Kompas Media Nusantara. UPN Veteran: Yogyakarta

Jayanti. Fitria Anugrah. 2014. Analisis Wacana Pada Pemilihan Gubernur Sulawesi Selatan Periode 2013-2018 di Kota Makassar. Universitas Hasanudin : Makassar

Kurniawan, Nanang Indra. 2012. Wacana Lingkungan dan Pembangunan berkelanjutan Dalam Lembaga Swadaya Masyarakat di Indonesia. JSP Volume 16, Nomor 1, Juli 2012 (1-15)

Payuyasa, I Nyoman. 2017. Analisis Wacana Kritis Model Van Dijk Dalam Program Acara Mata Najwa di Metro TV. Jurnal Segara Widya 14-24

Ramanathan, renugah \& Hoon, Tan bee. Application of Critical Discourse Analysis in Media Discourse Studies. The Southeast Asian Journal of English Language Studies-Vol21(2):57-68

Suciartini, Ni Nyoman Ayu. 2017. Analisis Wacana Kritis "Semua Karena Ahok" Program Mata Najwa Metro TV. Jurnal Aksara, Vol.29, No.2, Desember 2017

Wati, Beti Winanjar. 2014. Analisis Wacana Kritis Berita Sosial dan Politik Surat Kabar Kedaulatan Rakyat. UNY: Yogyakarta

Yenrizal. 2003. Budaya 'Politik Kulit' dan Komunikasi Politik Demokratis di Indonesia. Mediator, Vol.4. No.1

Yenrizal, Izomiddin. 2017. Strategi Komunikasi Politik Berbasis Isu Lingkungan Pada Pemilihan Umum Kepala Daerah Palembang 2018. Prosiding Konferensi Perkumpulan Dekal Ilmu Sosial 
Community: Volume 4, Nomor 2, Oktober 2018

ISSN: $2477-5746$

Yuniawan, Tommy, Rokhman, Fathur, Rustono.,etal. 2017. The Study of Critical EcoLinguistic in Green Discourse: Prospective Eco-Linguistic Analysis.Jurnal Humaniora Vol.29.pg 291-300 